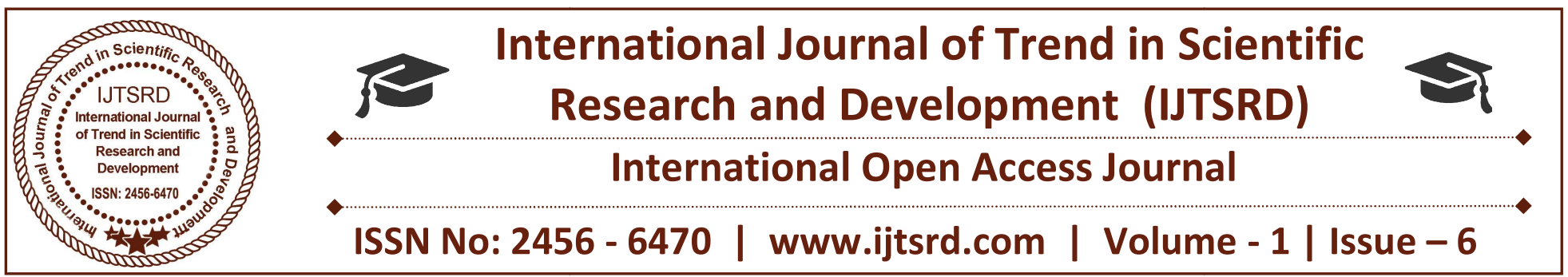

\title{
Effect of Normalization Techniques on Multilayer Perceptron Neural Network Classification Performance for Rheumatoid Arthritis Disease Diagnosis
}

\author{
Ali Osman Özkan \\ Department of Electrical and Electronics Engineering \\ Necmettin Erbakan University, Konya, Turkey
}

\begin{abstract}
In this study, Doppler signals were recorded from 40 healthy volunteers and the right and left hand ulnar and radial arteries of 40 rheumatoid arthritis patients. Multiple Signal Classification method, one of the subspace signal processing methods is applied to the obtained Doppler signals and the feature of signs has been reached. Diseased and healthy people have been distinguished by using three different normalization techniques, including (z-score, minimum-maximum and decimal scaling) and artificial neural networks classification. K-fold cross-validation, classification accuracy, sensitivity and specificity are used to interpret and described the results of medical diagnostic test.
\end{abstract}

Keywords: ANN, MUSIC, Rheumatoid arthritis, normalization techniques, Ulnar and Radial arteries

\section{INTRODUCTION}

Rheumatoid arthritis (RA) is a chronic and, systemic inflammatory disease, cause of which is unknown. Although the cause of RA disease has not been yet explained fully, the relationship between RA and genetic factors and autoimmunity (body works against its own tissues) is determined. Because it affects many joints at the same time, it causes deformities, labor force loss and major diseases. RA can be seen anywhere in the world and in every society. RA disease is most frequently observed for the age

between 30 and 50 years. While the incidence rate is $1 \%$ in developed countries, this rate is $0.1 \%$ in Turkey. It is more often in women than in men $(3 / 1)$ [1-3].

The diagnosis of RA disease is not still achieved clinically. A clinical diagnostic criterion is established by the American College of Rheumatology in 1987, and these criteria were revised in 1994. Then, RA classification criteria, determined by ACR / EULAR (American College of Rheumatology / European League Against Rheumatism) in 2010 and still valid today, is used. There are three basic laboratory tests for RA including, erythrocyte sedimentation rate, $\mathrm{C}$ reactive protein and anti-citrulline protein antibodies level, showing the correlation with disease severity, [4-7].

Doppler ultrasound is widely used as a noninvasive method for the assessment of blood flow in both the central and peripheral circulation [8]. Doppler ultrasound is a method used to examine the blood flow velocity, the direction and the blood flow rate. Because of ultrasonic waves, sent by the ultrasonic converter, scattering and reflection of red blood cells in the blood, change in frequency is observed in Doppler systems [8]. The difference between the transmitted wave frequencies to intravenous with the retro reflected wave frequency is called Doppler shift frequency and it is defined by the following equation. 


$$
\mathrm{f}_{\mathrm{d}}=\mathrm{f}_{\mathrm{t}}-\mathrm{f}_{\mathrm{r}}=\frac{2 \mathrm{v} \operatorname{Cos} \theta}{\mathrm{c}} \mathrm{f}_{\mathrm{t}}
$$

Here, $f_{d}$ is the mean Doppler shift frequency, $f_{t}$ is the frequency of the ultrasonic wave sent to the vein, $\mathrm{f}_{\mathrm{r}}$ is the frequency of ultrasonic waves reflected back from the vein, $\quad \mathrm{v}$ is the speed of the particles in the blood, $\mathrm{c}$ is the speed of the ultrasonic waves in the ambient and $\theta$ is the Doppler angle [9-10].

In this study, as spectral analysis method the Multiple Signal Classification (MUSIC) method has been used to extract the significant features from the right and left hand Ulnar and Radial arteries Doppler signals for diagnosing the RA disease. MUSIC method model with degrees of $5,10,15,20$, and 25 were used in the process of feature extraction from the Doppler signals belonging to the right and left hand Ulnar and Radial arteries. MUSIC spectral analysis method is used to transform Doppler signals from the time domain to the frequency domain. The MUSIC method was proposed by R.O. Schmidt in 1979 as an improvement to Pisarenko's method [11].

Artificial neural networks (ANN) method is widely used especially in biomedical signal processing. The concept of ANN has emerged with the idea of mimicking the brain's working principles on digital computers. The human brain makes a completely different way operation than traditional computer. ANN has complex, non-linear and parallel distributed structure. ANN is a designed structure to model of the performance of a particular job or a function of the brain. The power of ANN stems arises from learning, generalization ability and ability to make parallel process. ANN is a system to use the parallel computing techniques, to establish the relationship between inputs and outputs with the connection between the artificial neurons, to produce complex and non-linear models [12].

The literature shows that studies have focused on images obtained from the RA disease by using devices such as Doppler ultrasound and magnetic resonance images in diagnosing RA disease [13-15]. Furthermore, there are also studies for the diagnosis of various diseases by means of Doppler ultrasound signals [16-17].

\section{Materials and Methods}

\section{A. People Participating in the Study and Acquisition Doppler Signal}

40 patients diagnosed with RA based on the criteria of American College of Rheumatology and 40 healthy volunteers have participated in this study. 40 RA patients and 40 healthy volunteers have been evaluated by specialist doctor in Necmettin Erbakan University, Meram Medical Faculty and in Physical Medicine and Rehabilitation. The right and the left hand ulnar and radial artery Doppler signals of both 40 RA patients (36 women, 4 men, 38-70 age range, $52 \pm 9.1$ average and standard deviation of age) and 40 healthy volunteers (36 women, 4 men, 44-72 age range, $56 \pm 8.6$ average and standard deviation of age) are recorded [18].

The ulnar and radial arteries carry blood to our hand in two vessels. While the ulnar artery moves from the inner part of the arm, the radial artery moves the part where the thumb.

Doppler ultrasound signals have been recorded by specialist doctors using General Electric Loqio S6 Doppler ultrasound equipment in the Radiology Department of Meram Medical Faculty of Necmettin Erbakan University. To obtain quality output, standard ultrasound probe angle is fixed to 60 degree with electronic straightening methods and manual orientation. In all tests performed on the patients and healthy subjects, the insonation angle and the presetting of the ultrasound were kept fixing. The sampling volume was placed within the center of the arterial. The amplification gain was carefully set to obtain a clean spectral output with minimized background noise on the spectral display. The system used to record and process the Doppler signals consists of two parts, Power Doppler ultrasound unit with $12 \mathrm{MHz}$ linear ultrasound probe and a laptop [18].

The Doppler audio signals taken from audio output of Power Doppler ultrasound device have sampled at $44.1 \mathrm{kHz}$ and have been transferred to the computer so that spectral analysis can be performed and properties of these signals can be removed [18]. The flow of designed system is shows in Figure 1. 


\begin{tabular}{|l|l|}
\hline $\begin{array}{l}\text { Measurement } \\
\text { of Doppler } \\
\text { signals }\end{array}$ & $\begin{array}{l}\text { Acquisition of left and right hand } \\
\text { Radial arterial Doppler signals }\end{array}$ \\
\hline $\begin{array}{l}\text { Feature } \\
\text { extraction } \\
\text { nrocess }\end{array}$ & $\begin{array}{l}\text { Feature extraction from Doppler } \\
\text { signals using the MUSIC spectral } \\
\text { analysis methods }\end{array}$ \\
\hline $\begin{array}{l}\text { Classification } \\
\text { using the } \\
\text { WFKA }\end{array}$ & $\begin{array}{l}\text { Classification of left and right } \\
\text { hand Radial arterial Doppler } \\
\text { signals as healthv and R A disease }\end{array}$ \\
\hline $\begin{array}{l}\text { Classification } \\
\text { results }\end{array}$ & Healthy or RA disease \\
\hline
\end{tabular}

Figure 1. Flow diagram of the designed system to obtain the Doppler signal and the classification.

\section{B. Spectral Analysis of Doppler Signal with MUSIC}

Although signs exist physically on the time axis, these are shown in the frequency axis because the sinusoidal component is considered to occur at different frequencies. Signs are shown on the frequency axis and it is named as spectrum. Spectral analysis methods are used to show the distribution of power that is included in any signal over the frequency range. Spectral analysis is divided into 3 parts in itself. These are non-parametric (classic) spectral analysis methods, parametric (modern) spectral analysis methods and the subspace-based spectral analysis methods. Although non-parametric signal processing methods are not very good due to lack of performance, these methods are have more advantageous than other methods in terms of the small load operation and ease of application [19-21].

MUSIC is an acronym which stands for multiple signal classification. It is high resolution technique based on exploiting the eigen-structure of input covariance matrix. The advantage of this algorithm is that it exhibits high resolution. The MUSIC method is also a noise subspace frequency estimator. The MUSIC method proposed by Schmidt [11] eliminates the effects of spurious zeros by using the averaged spectra of all of the eigenvectors corresponding to the noise subspace. The resultant PSD is determined from:

$$
\mathrm{P}_{\text {Music }}(\mathrm{f})=\frac{1}{\left(\frac{1}{\mathrm{~K}}\right) \sum_{\mathrm{i}=0}^{\mathrm{K}-1}\left|\mathrm{~A}_{\mathrm{i}}(\mathrm{f})^{2}\right|}
$$

Where $\mathrm{K}$ the dimension of noise is subspace and $A_{i}(f)$ is the desired polynomial that corresponds to all the eigenvectors of the noise subspace [11].

\section{Normalization Methods}

Normalization method is a data pre-processing technique used to enhance the performance of the artificial intelligence systems. Normalization process is to move the data set with $m x n$ size from one space to another space. New maximum and minimum points are occurred in transport operation but there is no change in the size of the data set $m x n$. If performed normalization method is appropriate for the transfer characteristics of artificial intelligence, obtained results become more successful. Especially, the transfer function has a special significance in the sarch for a solution based on ANN. Logsig transfer function is the transfer function commonly used in neural network applications and it makes data normalization to the $0-1$ range [22-24]. Whatever type of normalization, data is normalized on the basis of column independently of each other especially in the data set with different properties. Each data column shows a feature in the data with discrete features and applies to separately each feature in normalization [22-24].

In the literature, there are many normalization methods. In this study, three most widely used normalization methods in engineering applications were used. These are minimum- maximum method, decimal scaling method and Z- score method [22-24].

Minimum-maximum normalization method normalizes the data linearly. While the minimum refers the lowest value in the corresponding column, the maximum refers the highest value in the corresponding column. Equation 3 indicated below is used to reduce the range of $0-1$ by minimummaximum normalization method.

$$
x=\frac{x_{i}-x_{\min }}{x_{\max }-x_{\min }}
$$


In Equation 3, the normalized data, the raw data, the smallest number of columns which the raw data is available and the biggest number of columns which the raw data is available [22-24].

Decimal scaling method is a division operation that makes numbers less than 1. Decimal scaling normalization process is shown in Equation 4.

$$
x=\frac{x_{i}}{10^{j}}
$$

According to Equation 4, $\mathrm{j}$ can be defined as the smallest value which makes the column values smaller than 1.

Z-Score used for statistical evaluation is data preprocessing method. Mean values and standard deviation of each column must be calculated to normalize values. Z-scores generate new values for the average value of the data with the distances from the average of these values. After the normalization of the Z-score, the average is obtained by a Gaussian distribution with zero. Z-score normalization process is shown in Equation 5.

$$
\mathrm{x}=\frac{\mathrm{x}_{\mathrm{i}}-\mu_{\mathrm{i}}}{\sigma_{\mathrm{i}}}
$$

In Equation 5, the normalized data, the raw data, the average of the raw data found in column and the standard deviation of the raw data found in column.

\section{Classification of the Doppler Signal with WEKA}

An artificial neural network (ANN) is a flexible mathematical structure which is capable of identifying complex nonlinear connections between input and output data sets. ANN models have been found useful and efficient, especially in problems for which the characteristics of the processes are difficult to describe using physical equations. The information in ANN situates in the weights of the connections between neurons. Training of the neural network is performed by adjusting the values of weights. Back propagation algorithm is one of the most widely used in biomedical signal processing algorithm [12]. Back propagation algorithm consists of 3 layers including input, hidden and output layers. In back propagation algorithm, because calculated error in output spreads from output layer to hidden layer after then, from hidden layer to input layer, this algorithm is called back propagation algorithm [24-25].

WEKA (Waikato Environment for Knowledge Analysis), developed by the University of Waikato in New Zealand, hosting with machine learning algorithms, a functional graphic interface, developed on the Java platform, open source code, is a data mining program. WEKA has emerged initially as a Project, but today being used by many people all over the world as a data mining application development program. WEKA includes various data preprocessing, classification, regression, clustering, association rules and visualization tools. Algorithms can be applied to the data set or calling directly from Java code [26].

MLP (Multi-Layer Perceptron), ANN algorithm, is used for the classification of problems that cannot be divided into two parts by a linear function. MLP used in this study consists of 129 features in the input layer, 66 neurons in the hidden layer and 2 neurons in the output layer (healthy or suffering from RA). Standard back-propagation algorithm is a method where a sloping landing foreseen to reach the minimum point on the failure surface. The weight values are updated every step in order to provide that $[12,24-25]$.

For the analysis of right and left hand ulnar and radial artery Doppler signals by using ANN, all parameters were kept constant.

\section{E. Conclusion}

Some statistical measurements are used to evaluate the performance of classifiers and normalization methods used in the classification of medical data sets. In this study, 10-fold cross with separate data sets, classification accuracy, sensitivity and specificity values are used in order to compare the classification performance.

In the training and testing of MLP-ANN, a data partition of 90-10\% (72-8) train-test was used. In our dataset, there are 40 patients with RA diseases and 40 healthy volunteers. In totally, 80 subjects were used to test the diagnosis of RA disease. The training input data set consisted of 36 normal and 36 RA patients 
International Journal of Trend in Scientific Research and Development (IJTSRD) ISSN: 2456-6470

(72x129 samples), while the test data set was made of 4 normal and 4 RA patients (8x129 samples). In order to evaluate the performance of the MLP-ANN models, Classification accuracy (CA), sensitivity (SEN) and selectivity (SPE) are calculated by the formulas shown below.

$$
\begin{aligned}
& \mathrm{CA}=\% \frac{\mathrm{TP}+\mathrm{TN}}{\mathrm{TP}+\mathrm{FP}+\mathrm{TN}+\mathrm{FN}} \times 100 \\
& \mathrm{SEN}=\% \frac{\mathrm{TP}}{\mathrm{TP}+\mathrm{FN}} \times 100 \\
& \mathrm{SPE}=\% \frac{\mathrm{TN}}{\mathrm{FP}+\mathrm{TN}} \times 100
\end{aligned}
$$

In the above equations, $\mathrm{TP}, \mathrm{FP}, \mathrm{TN}$ and $\mathrm{FN}$ are true positive, false positive, true negative and false negative, respectively.

TP: RA patient identifying as RA patient

FP: A healthy person identifying as RA patient

TN: A healthy person identifying as normal

FN: RA patient identifying as normal

In this study, all procedures were performed with WEKA machine learning program. The test result of MLP-ANN classifier are shown in TABLE I. for the right and left ulnar artery Doppler signals obtained by 10 -fold cross validation.

The value of the classification accuracy (CA), sensitivity (SEN) and specificity (SPE) of MLP-ANN classifier are shown in TABLE II for the right and left ulnar artery Doppler signals are obtained by 10 -fold cross validation.

TABLE I. THE TEST RESULT OF MLP-ANN CLASSIFIER ARE OBTAINED BY 10-FOLD CROSS VALIDATION

\begin{tabular}{|l|l|l|l|l|}
\hline \multicolumn{1}{|c|}{$\begin{array}{c}\text { The Right Ulnar } \\
\text { Artery }\end{array}$} & TP & FP & TN & FN \\
\hline Raw Data & 33 & 7 & 32 & 8 \\
\hline Min- Max & 36 & 4 & 38 & 2 \\
\hline Z- Score & $\mathbf{3 7}$ & $\mathbf{3}$ & $\mathbf{3 8}$ & $\mathbf{2}$ \\
\hline Decimal Scaling & 36 & 4 & 38 & 2 \\
\hline The Left Ulnar Artery & TP & FP & TN & FN \\
\hline Raw Data & 32 & 8 & 31 & 9 \\
\hline Min- Max & 35 & 5 & 35 & 5 \\
\hline Z- Score & $\mathbf{3 7}$ & $\mathbf{3}$ & $\mathbf{3 7}$ & $\mathbf{3}$ \\
\hline Decimal Scaling & 36 & 4 & 36 & 4 \\
\hline The Right Radial Artery & TP & FP & TN & FN \\
\hline Raw Data & 35 & 5 & 33 & 7 \\
\hline Min- Max & 37 & 3 & 38 & 2 \\
\hline Z- Score & $\mathbf{3 9}$ & $\mathbf{1}$ & $\mathbf{3 9}$ & $\mathbf{1}$ \\
\hline Decimal Scaling & 38 & 2 & 38 & 2 \\
\hline The Left Radial Artery & TP & FP & TN & FN \\
\hline Raw Data & 35 & 5 & 35 & 5 \\
\hline Min- Max & 37 & 3 & 38 & 2 \\
\hline Z- Score & $\mathbf{3 8}$ & $\mathbf{2}$ & $\mathbf{3 9}$ & $\mathbf{1}$ \\
\hline Decimal Scaling & 37 & 3 & 38 & 2 \\
\hline
\end{tabular}

TABLE II. THE VALUE OF THE CLASSIFICATION ACCURACY (CA), SENSITIVITY (SEN) AND

\begin{tabular}{|c|c|c|c|}
\hline $\begin{array}{l}\text { The Right } \\
\text { Ulnar Artery }\end{array}$ & $\begin{array}{l}\text { CA } \\
(\%)\end{array}$ & $\begin{array}{l}\text { SEN } \\
(\%)\end{array}$ & $\begin{array}{l}\text { SPE } \\
(\%)\end{array}$ \\
\hline Raw Data & 81.25 & 80.49 & 82.05 \\
\hline Min - Max & 92.5 & 94.74 & 90.48 \\
\hline Z- Score & 93.75 & 94.87 & 92.68 \\
\hline Decimal Scaling & 92.5 & 94.74 & 90.48 \\
\hline $\begin{array}{l}\text { The Left } \\
\text { Ulnar Artery }\end{array}$ & $\begin{array}{l}\text { CA } \\
(\%)\end{array}$ & $\begin{array}{l}\text { SEN } \\
(\%)\end{array}$ & $\begin{array}{l}\text { SPE } \\
(\%)\end{array}$ \\
\hline Raw Data & 78.75 & 78.05 & 79.49 \\
\hline Min - Max & 87.5 & 87.5 & 87.5 \\
\hline Z-Score & 92.5 & 92.5 & 92.5 \\
\hline Decimal Scaling & 90 & 90 & 90 \\
\hline $\begin{array}{l}\text { The Right } \\
\text { Radial Artery }\end{array}$ & $\begin{array}{l}\text { CA } \\
(\%)\end{array}$ & $\begin{array}{l}\text { SEN } \\
(\%)\end{array}$ & $\begin{array}{l}\text { SPE } \\
(\%)\end{array}$ \\
\hline Raw Data & 85 & 83.33 & 86.84 \\
\hline Min - Max & 93.75 & 94.87 & 92.68 \\
\hline Z- Score & 97.5 & 97.5 & 97.5 \\
\hline Decimal Scaling & 95 & 95 & 95 \\
\hline $\begin{array}{l}\text { The Left } \\
\text { Radial Artery }\end{array}$ & $\begin{array}{l}\text { CA } \\
(\%)\end{array}$ & $\begin{array}{l}\text { SEN } \\
(\%)\end{array}$ & $\begin{array}{l}\text { SPE } \\
(\%)\end{array}$ \\
\hline Raw Data & 87.5 & 87.5 & 87.5 \\
\hline Min - Max & 93.75 & 94.87 & 92.68 \\
\hline Z- Score & 96.25 & 97.44 & 95.12 \\
\hline Decimal Scaling & 93.75 & 94.87 & 92.68 \\
\hline
\end{tabular}
SELECTIVITY (SPE) OF MLP-ANN CLASSIFIER ARE OBTAINED BY 10-FOLD CROSS VALIDATION 
Consequently, it is seen that the classification result of all normalization method is better than raw data in TABLE I and II. Therefore, it obviously proves that using the normalization method is necessary for preprocessing of data. According to the result in TABLE II, when classification accuracy has been compared, z-score normalization appears to be 93.75 $\%$ in the right ulnar artery, $92.5 \%$ in the left ulnar artery, $97.5 \%$ in the right radial artery and $96.25 \%$ in the left radial artery for the right and left ulnar and radial artery Doppler signals. Therefore, it can be concluded that Z-score normalization method provides better results than other examined normalization methods for the right and left ulnar and radial artery Doppler signals.

\section{Acknowledgment}

This work is supported by the Scientific Research Projects of Necmettin Erbakan University.

\section{References}

[1] V. Hamuryudan, "Romatoid artrit", İ.Ü. Cerrahpaşa Tıp Fakültesi Sürekli Tıp Eğitimi Etkinlikleri, Türkiye'de Sik Karşılaşılan Hastalıklar-I, Enfeksiyon Hastalıkları, Romatizmal Hastaliklar, Afetlerde Ezilme Yaralanmaları, Sempozyum Dizisi No:55, pp. 6986, 2007.

[2] G. Hatemi and H. Yazıc1, "Romatoid artrit kliniği”, Türkiye Klinikleri J. Int. Med. Sci., vol.2, No:25, pp:12-17, 2006.

[3] D. M. Lee and M. E. Weinblatt, "Rheumatoid arthritis", The Lancet 358, pp. 903-911, 2001.

[4] S. Özgöçmen, H. Özdemir, A. Kiriş, Z. Bozgeyik and O. Ardiçoğlu, "Clinical evaluation and power Doppler sonography in rheumatoid arthritis: Evidence of ongoing synovial inflammation in clinical remission", Southern Medical Journal, vol. 101, pp. 240-245, 2008.

[5] L. Carmona, V. Villaverdei, C. H. Garcia, J. Ballina, R. Gabriel and A. Laffon, "The prevalence of rheumatoid arthritis in the general population of Spain", Rheumatology, vol. 41, pp. 88-95, 2002.

[6] H. Elden and V. Nacitarhan, "Romatoid artritli hastalarda sabah tutukluğu ile akut faz reaktanlarının korelasyonu", Türk Fiziksel Tip Rehabilitasyon Dergisi, vol. 51, No:1, pp. 19-21, 2005.

[7] R. Y1ldırım and Y. Yazıc1, "Romatoid artritte erken tedavi", RAED Dergisi, vol. 4, No:2, pp. 59-67, 2012.
[8] D. H. Evans, W. N. McDicken, R. Skidmore and J. P. Woodcock, "Doppler ultrasound: Physics, instrumentation and clinical applications", Wiley, Chichester, 1989.

[9] F. S. Schlindwein and D. H. Evans, "A real-time spectrum analyzer for Doppler ultrasound signals", Ultrasound Med. Biol., vol. 15, No:3, pp. 263-272, 1989.

[10] B. Sigel, "A brief history of Doppler ultrasound in the diagnosis of peripheral vascular disease", Ultrasound Med. Biol., vol. 24, No:2, pp. 169-176, 1998.

[11] R. O. Schmidt, "Multiple emitter location and signal parameter estimation", IEEE Transactions on Antennas Propagation, Vol. AP-34, No:3, pp. 276-80, March 1986.

[12] S. Haykin, "Neural networks: A comprehensive foundation", Macmillan, New York, 1994.

[13] K. Varsamidis, E. Varsamidou, V. Tjetjis and G. Mayropoulos, "Doppler sonography in assessing disease activity in rheumatoid arthritis", Ultrasound in Medicine \& Biology, vol. 31, No:6, pp. 739-743, 2005.

[14] A. Kiriş, S. Özgöçmen, E. Kocakoç and Ö. Ardıçoğlu, "Power doppler assessment of overall disease activity in patients with rheumatoid arthritis", Journal of Clinical Ultrasound, vol. 34, No:1,pp. 5-11, 2006.

[15] J. Strunk, P. Klingenberger, K. Strube, G. Bachmann, U. Müller-Ladner and A. Kluge, "Three-dimensional doppler sonographic vascular imaging in regions with increased MR enhancement in inflamed wrists of patients with rheumatoid arthritis", Joint Bone Spine, vol. 73, pp. 518-522, 2006.

[16] F. Dirgenali, S. Kara, N. Erdoğan, M. Okandan, "Comparison of the autoregressive modeling and fast Fourier transformation in demonstrating Doppler spectral waveform changes in the early phase of atherosclerosis", Computers in Biology and Medicine, vol. 35,pp. 57-66, 2005.

[17] S. Kara, "Classification of mitral stenosis from Doppler signals using short time Fourier transform and artificial neural networks, Expert Systems with Applications, vol. 33, pp. 468-475, 2007.

[18] A. O. Özkan, "Investigation of changes in Radial and Ulnar artery blood flow during the treatment process of Rheumatoid Arthritis Patients", The Graduate School of Natural and 
Applied Science of Selçuk University, Ph.D Thesis, 2010.

[19] M. H. Hayes, "Statistical Digital Signal Processing and Modeling", John Wiley \& Sons, Inc., 1996.

[20] J. L. Semmlow, "Biosignal and Biomedical Image Processing MATLAB-Based Applications", Robert Wood Johnson Medical School New Brunswick, New Jersey, 2004.

[21] A. O. Özkan, S. Kara, A. Sall, M. E. Sakarya, S. Güneş, "Medical diagnosis of rheumatoid arthritis disease from right and left hand Ulnar artery Doppler signals using adaptive network based fuzzy inference system (ANFIS) and MUSIC method", Advances in Engineering Software, vol. 41, Issue 12, pp. 1295-1301, 2010.

[22] A. O. Özkan, S. Durğun, "Normalizasyon Tekniklerinin Romatoid Artrit Hastalı̆ için YSA Sınıflama Performansına Etkisi"; pp 147-152; EEB 2016 Elektrik-Elektronik ve Bilgisayar Sempozyumu, 11-13 Mayıs 2016, Tokat -TÜRKIYE
[23] B. Akdemir, "A new approach to normalization methods for improving performance on the prediction applications", The Graduate School of Natural and Applied Science of Selçuk University, Ph.D Thesis, 2009.

[24] B. Widrow and M. A. Lehr, "30 years of adaptive neural networks: Perceptron, madaline, and backpropagation", Proc. IEEE, vol. 78-9, pp. 1415-1442, 1990.

[25] B. B. Chaudhuri and U. Bhattacharya, "Efficient training and improved performance of multilayer perceptron in pattern classification", Neurocomputing 34, pp. 11-27, 2000.

[26] http://www.cs.waikato.ac.nz/ml/weka/[Ziyaret Tarihi: 2 Eylül 2017] 